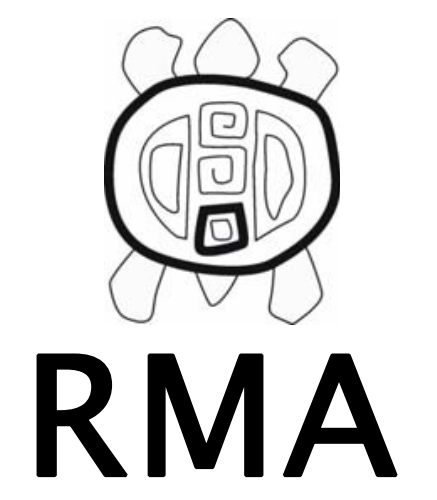

Antropología Forense

\title{
Una fosa común en el interior de Argentina: el Cementerio de San Vicente
}

\author{
Darío Olmo \\ Mercedes Salado Puerto \\ Equipo Argentino de Antropología Forense \\ Museo de Antropología, Facultad de Filosofía y Humanidades \\ Universidad Nacional de Córdoba. \\ d_olmo@yahoo.com
}

\begin{abstract}
Resumen
La Antropología Forense ha tenido un papel fundamental en las investigaciones sobre el terrorismo de estado en Argentina durante el último siglo, y todavía lo tiene: La exhumación de los cadáveres no identificados enterrados en fosas comunes y tumbas individuales y el análisis de los restos recuperados para su identificación y determinación de la causa de muerte. En el caso aquí descrito, las técnicas forenses y arqueológicas son esenciales para la localización de las fosas comunes en San Vicente, Córdoba, distinguiendo entre los desaparecidos y otros muertos allí enterrados, la determinación de la identidad y la reconstrucción de la forma en que fueron asesinados.
\end{abstract}

Palabras clave: Antropología Forense, Terrorismo de estado, Cementerio San Vicente Córdoba, Identificación de desaparecidos.

A common grave in Argentina interior. The San Vicente Cemetery.

\section{Abstract}

Forensic anthropology had a fundamental role to play in the process of investigations about State Terrorism in Argentina during the last century, and still does: that of exhuming the unidentified bodies still buried in common and individual graves and of analyzing the recovered remains towards their identification and determination of the cause of death. In the case described here, forensic anthropological and archaeological skills were essential in locating the mass graves at San Vicente, Córdoba, distinguishing among disappeared and non-disappeared dead, determining identity, and reconstructing the manner in which the disappeared were killed.

Keywords: Forensic Anthropology, State terrorism, Cordoba San Vicente's Cemetery, disappeared people identification.

\section{Introducción}

El siglo XX constituyó, para la formación política conocida como la República Argentina, un período de intensa inestabilidad institucional. Los sectores dominantes, que habían definido el perfil del país en el siglo XIX, no lograron producir una opción que resistiera la incorporación del sistema republicano, representativo y federal proclamado por la propia constitución. El voto obligatorio para la ciudadanía, que comenzara a ejercitarse en 1916 (y que en 1947 se hizo extensivo a la mitad femenina de la población), no lograba expresar una armonía entre los distintos sectores sociales sino más bien era una válvula para la emergencia de tensiones, que no lograban ser contenidas dentro del sistema republicano. En este marco, las Fuerzas
Armadas se convirtieron en el brazo armado de los sectores dominantes, y en el árbitro que interrumpía la vigencia de los gobiernos elegidos por el voto de la ciudadanía. Este ciclo de constantes golpes militares y de gobiernos constitucionales inconclusos solo se interrumpió luego de que una nueva dictadura militar condujera al país a un conflicto bélico contra una potencia de la NATO (la guerra de Malvinas, en 1982), que redundó en el definitivo desprestigio de los militares y su incapacidad para ofrecerse como una opción de gobierno frente a cualquier sector de opinión pública. Esta derrota militar se sumó a la condena internacional que cosechó la política de masivas violaciones a los Derechos Humanos de aquella dictadura, y que son el emblema de una época aciaga. Este marco de 
peculiar debilidad en la retirada militar quizás ayude a explicar los avances producidos en Argentina en cuanto a investigación y castigo de aquellas violaciones a los Derechos Humanos del período 1976 - 1983, que en este país alcanzaron marcas nunca igualadas entre sus vecinos del cono sur. Efectivamente, ni en Chile, ni en Brasil, Uruguay, Paraguay, Bolivia o Perú la sanción de los responsables del terrorismo de estado y la reparación a las víctimas alcanzó la magnitud de lo producido en Argentina en las últimas décadas del siglo pasado. En este marco se produjo el surgimiento y consolidación de la Antropología Forense en Argentina, con una fuerte inclinación a los estudios sobre violaciones a los Derechos Humanos de las décadas anteriores y la disposición a aplicar estos conocimientos en otras regiones del Tercer Mundo afectadas también por este tipo de problemas. Desde 1984 a la fecha, el trabajo del Equipo Argentino de Antropología Forense se ha difundido por cuarenta países de los cinco continentes, transformando a la organización en una referencia obligada a nivel nacional e internacional. Las líneas que siguen intentan describir un caso de investigación en el interior de Argentina, de fuerte resonancia local y nacional y que posee rasgos que lo hacen peculiar y significativo.

\section{El Caso del Cementerio de San Vicente en la ciudad de Córdoba: Antecedentes}

La ciudad de Córdoba es capital de la provincia del mismo nombre. Segunda en importancia de la República Argentina, con más de un millón de habitantes, la ciudad se ubica a 800 kilómetros al noroeste de Buenos Aires, en el centro geográfico del país. Sede de la universidad más antigua de la Argentina, en la segunda mitad del siglo XX se transformó en un polo industrial de envergadura, con el desarrollo de numerosos establecimientos dedicados a trabajos de la industria metalúrgica, automotor y energía. Este crecimiento no fue ajeno a las vicisitudes de la vida económica y política argentina, en el que las discontinuidades conceptuales de los distintos gobiernos estimulaban o desalentaban la inversión y le desarrollo. Una enérgica revuelta popular masiva, conocida como el Cordobazo, en mayo de 1969, significó la sentencia que descalificaba definitivamente a la dictadura militar que gobernaba el país en ese entonces. Desde ese entonces, Córdoba se transformó en una usina fundamental del estado de movilización y cuestionamiento que atravesó a la sociedad argentina en esos años. Los sindicatos combativos y los estudiantes radicalizados se manifestaban como la punta de lanza de una sociedad disconforme y dispuesta a una aguda transformación social. La respuesta de los sectores hegemónicos de la sociedad no se haría esperar. El golpe de estado del 24 de marzo de 1976 puso fin a un turbulento período democrático e instauró un régimen que adoptó el terrorismo de estado como forma de gobierno. En ese marco, todos los derechos que la Constitución Argentina otorga a los ciudadanos fueron denegados por el propio gobierno, que alcanzó un registro escandaloso de violaciones masivas y sistemáticas a los Derechos Humanos. La figura emblemática de esta política de estado lo constituye el Desparecido, aquel cuyo paradero se desconoce, pero se presume cautivo de la maquinaria represiva oficial. La incertidumbre sobre la situación de miles de ciudadanos y la negativa oficial a rendir cuenta de sus actos son los rasgos más conspicuos de este período. Esto es particularmente acertado para describir lo ocurrido en Córdoba, donde la maquinaria de represión ilegal se inició aún antes que en el resto del país. En febrero de 1974, a ocho meses de instaurado un gobierno provincial resultante de elecciones sin proscripciones, el Gobernador y el Vicegobernador fueron depuestos por el Jefe de Policía, y la provincia fue intervenida por el Gobierno Federal. A partir de entonces se instauró un gobierno autoritario y represivo, que combatió la movilización y ensayó varias de las políticas que luego se harían masivas y extensivas a todo el país. A la instauración del Estado de Sitio le siguió un incremento notable de las detenciones ilegales, denuncias de torturas a detenidos y la desaparición forzada de decenas de ciudadanos. También se cuentan en por cientos los cadáveres abandonados en la periferia de la ciudad, con signos de tortura y acribillados a balazos. A partir de marzo de 1976, la puesta en marcha de toda la maquinaria de un Estado moderno al servicio de un plan de exterminio de una parte de la población, ya no conoció límites. El saldo es posible estimarlo a posteriori, gracias al trabajo de la delegación local de la CONADEP, la comisión de la verdad designada por el Ejecutivo tras la restauración democrática, a fines de 1983. También, por los importantes avances en el conocimiento del tema que produjeron las investigaciones de la Justicia Federal de Córdoba después del año 2000. Estos trabajos, junto a las investigaciones de los organismos de defensa de los Derechos Humanos, permiten estimar en más de 800 los casos fehacientes de desaparición forzada de personas para la región de la ciudad de Córdoba y alrededores, para el intervalo 1975 - 1983.

El ocultamiento de los detenidos y, tras la aplicación de la pena capital, de sus cadáveres, se transformó en una de las características más perturbadoras del sistema represivo. De éste se pueden predicar dos características fundamentales y definitorias: territorialidad y clandestinidad. La primera refiere a su forma de ocupar el espacio, según la cadena de mandos y las unidades (Cuerpo, Brigada, Regimiento, Batallón) en las que se organizaba el Ejército Argentino. El país se dividía en cinco Cuerpos de Ejército, cada uno de ellos responsable de la llamada guerra contra la subversión en la porción asignada del territorio 
nacional. El Comando del III Cuerpo de Ejército funcionaba en la ciudad de Córdoba, y tenía responsabilidad sobre lo actuado en ésta y otras nueve provincias del centro, oeste y noroeste del país, un territorio de más de un millón de kilómetros cuadrados. Esta era la llamada Zona III, dividida en subzonas, áreas y subáreas de acuerdo al criterio de unidades del Ejército antes mencionado. Cada una de estas secciones del territorio estaba bajo el mando de la unidad militar local y bajo la órbita de estas funcionaron los Centros Clandestinos de Detención (CCD) donde se hacinaba a los prisioneros (ciudadanos cuya detención el Estado no reconocía), y se los sometía a una serie de vejámenes más o menos constante (tortura, juicio, ejecución o sobrevida). Simultáneamente, el estado terrorista desplegaba un simulacro de normalidad y de vigencia de la ley, apoyado por una parte de la población que acompañaba el restablecimiento del orden a cualquier precio.

En el caso de la ciudad de Córdoba y zona de influencia, se destacó un CCD que dependía de la Brigada Aerotransportada que funcionaba en las afueras de la ciudad, conocido como La Perla. Se estima que la mayoría de los desaparecidos en la región pasaron por este sitio y en él se decidió la suerte corrida por los detenidos, que en la enorme mayoría de los casos devino en una muerte anónima. En algunas ocasiones los grupos de tareas de la represión ilegal fraguaban enfrentamientos armados entre grupos sediciosos y tropas regulares. De esta manera, algunos desaparecidos «reaparecían» con posterioridad a su secuestro, bajo la forma de muertos en enfrentamientos. En varios casos se verificaron enfrentamientos reales también. En estas ocasiones, fueran los enfrentamientos fraguados o reales, los cuerpos de las personas muertas eran llevados a la Morgue Judicial de la ciudad, que funcionaba en un hospital público. Las frecuentes series de asesinatos múltiples, que son la constante en Argentina y Córdoba en particular durante la segunda mitad de la década del setenta, provocaban la rápida saturación de esta morgue, creando situaciones sanitarias conflictivas en establecimientos destinados a la salud pública. Esto generó que se dispusieran enterramientos masivos y clandestinos de cientos de cuerpos en áreas marginales de cementerios municipales. Se pudo verificar no menos de cuatro episodios de ésta índole para el año 1976 en San Vicente, el cementerio más frecuentemente utilizado por los sectores de menores recursos en la ciudad de Córdoba.

La existencia de estas fosas comunes se conoció a través de un episodio particularmente bizarro: En 1980 un grupo de empleados de la Morgue Judicial, cansados de reclamar un sobresueldo por tareas insalubres y no ser escuchados por las autoridades locales, enviaron una carta al general Videla, en aquel entonces a cargo de la Presidencia de la Nación y máximo responsable de la política terrorista en la que se encontraba involucrado el estado argentino.
En esa carta, para apoyar sus reclamos, daban como ejemplo las barbaridades que debieron cometer en 1976, y los episodios en los cuales llevaron decenas y decenas de cadáveres descompuestos a San Vicente, en horas de la noche. La respuesta oficial fue un sumario administrativo, por haberse dirigido a instancias superiores sin pasar por las intermedias, y la cesantía de los firmantes. En 1984, cuando funcionó la CONADEP se tomó noticia de la carta y para la Justicia y la opinión pública de Córdoba se instaló la convicción de la existencia de fosas comunes en San Vicente. Ese año, la Justicia Federal ordenó excavaciones en un sector del cementerio, señalado por uno de los morgueros que escribió la carta de 1980. Esta excavación se realizó con palas mecánicas y personal del cementerio, sin tomar los mínimos recaudos para la recuperación de los restos y un tratamiento científico de las evidencias. El saldo de estas excavaciones lo fue la identificación del cráneo de una mujer, del cual se comparó la dentadura con la ficha odontológica de quien se sospechaba podía ser (una desparecida en otra ciudad) y la destrucción de una fosa común conteniendo una cifra incalculable de esqueletos humanos, que poco después fueran derivados al horno crematorio del mismo cementerio, por orden de autoridades municipales democráticamente elegidas.

Este resultado tan poco alentador y la actitud claudicante del gobierno hicieron que las investigaciones judiciales se detuvieran y que los militares acusados ante las cortes recuperaran la libertad y la impunidad. En ese marco, no volvió a investigarse lo ocurrido en San Vicente hasta principios del nuevo milenio.

A principios de los 2000, un Juzgado Federal de Córdoba retomó las investigaciones, en un clima político más hospitalario. Efectivamente, en esos años el Congreso Nacional derogó las leyes que garantizaban la impunidad de los imputados por crímenes contra la humanidad y la justicia aceptó las causas presentadas por familiares de desaparecidos contra los responsables de esos hechos. Esto sucedió en Córdoba y en ese marco fuimos convocados para verificar la existencia de remanentes de la fosa común en San Vicente.

Si algún rasgo peculiar debe señalarse de los trabajos de Córdoba, en comparación con los otros desarrollados por el EAAF en decenas de sitios en Argentina es el involucramiento de la sociedad como un todo en el buen suceso de las investigaciones: a la buena disposición y cooperación del Juzgado Federal interviniente, debe añadirse un actor clave: la Facultad de Filosofía y Humanidades de la Universidad Nacional de Córdoba, lo que supuso un aporte logístico y de personal considerable, materializado por las autoridades de la Facultad y el Museo de Antropología que de estas depende. Los organismos de Derechos Humanos y la prensa local, sindicatos, los gobiernos provincial, municipal y nacional, de diverso signo político, 
colaboraron con la financiación de los trabajos, que mayormente fue cubierto por la Embajada del Reino de los Países Bajos en Argentina. La Justicia Provincial nos asignó un lugar permanente como Laboratorio de Antropología Forense en la Morgue Judicial. Genetistas del ámbito privado aportaron la identificación por comparación de segmentos de ADN, historiadores (más precisamente una Cátedra de Historia Argentina a cargo de Mónica Gordillo y Laura Valdemarca) y la organización no gubernamental ARHISTA reunieron la información sobre cada persona desparecida en el área y contribuyeron a un sólido conocimiento sobre lo sucedido durante los años setenta. De esta manera, se fue desarrollando la Investigación Preliminar, que permitió abordar las restantes etapas del trabajo sobre bases firmes.

\section{Informe Arqueológico}

Las excavaciones arqueológicas en el Cementerio de San Vicente, en la ciudad de Córdoba, se desarrollaron en el marco de la causa «Averiguación de Enterramientos Clandestinos», que se tramita ante el Juzgado Federal $N^{\circ} 3$, a cargo de la Doctora Cristina Garzón de Lascano (Olmo 2005). En la primera quincena de Febrero de 2003, se iniciaron las excavaciones en el Sector $\mathrm{C}$ del Cementerio de San Vicente. Se consideró como clave en la localización de los sitios buscados el testimonio presentado en su oportunidad por el Sr. Caro, funcionario de la Morgue de Córdoba que participó de las inhumaciones de 1976 y se acercó hasta el cementerio para indicar los lugares correspondientes a las fosas comunes excavadas en aquel entonces. La veracidad de sus apreciaciones se pudo verificar en las exhumaciones no científicas practicadas en 1984. Siguiendo esas indicaciones, se practicaron una serie de trincheras en el sector, intentando abarcar la mayor cantidad de terreno sin afectar las sepulturas posteriores. Estas trincheras resultaron arqueológicamente estériles, pero nos permitieron formarnos una idea de la estratigrafía del Sector C. Esta parte del Cementerio de San Vicente constituía, en los tiempos de los episodios investigados, la zona posterior de la necrópolis, y las fotografías aéreas de los años setenta / ochenta que se consiguieron, permiten constatar que su utilización para la práctica de inhumaciones es posterior a 1974. Por otra parte, el examen de las capas superficiales del terreno removido, avala la presunción que, los primeros treinta centímetros de los terrenos adyacentes a la calle que separa al Sector $C$ de los panteones y el horno crematorio, corresponde a un relleno sedimentario de origen antrópico (esto es, no natural), probablemente redepositado en el transcurso de las obras de pavimentado de la calle, en algún momento entre 1977 y 1978 . Se trata de un orgánico magro, con presencia de numerosos guijarros y rodados de tosca. Profundizando, se verifica la existencia de sedimentos eólicos y otros compatibles con la cercanía de antiguos cauces fluviales.

Vista la esterilidad de las trincheras excavadas, decidimos, a partir del día 17 de Febrero, desplazarnos unos metros hacia el Este y comenzar a sondear en la continuación de la línea que separa a la excavación de 1984 del Crematorio, en la parte de la sección C más cercana a éste, enfrentándolo, calle de por medio. Por su ubicación relativa respecto al resto del Sector C, Ilamamos a este lugar Cabecera Norte del Sector C.

Mientras se continuaba trabajando cerca de la calle pavimentada se mantuvieron entrevistas con personas que estuvieron presentes en las exhumaciones ordenadas en 1984, de modo de comprender mejor la dinámica sufrida por el sitio. Todo el lugar fue rodeado por una cerca que impedía la vista de curiosos y mientras no se excavaba permanecía una guardia de la policía garantizando la seguridad del sitio. La superficie delimitada era de alrededor de 2000 metros cuadrados. En el transcurso de la segunda mitad de Febrero los trabajos iniciados en la Cabecera Norte comenzaron a dar resultados compatibles con lo esperado. En toda excavación arqueológica encarada en un cementerio en funcionamiento es recomendable desestimar el seguimiento de la estratigrafía natural, ya que es legítimo suponer la distorsión de aquella por las constantes intrusiones que cada episodio de inhumación significa. Por esta razón desechamos una excavación por capas naturales y establecimos niveles artificiales de veinte (20) centímetros de espesor. Desde el segundo nivel así definido y excavado se hizo evidente la presencia de restos óseos humanos, desarticulados, en una matriz de residuos de ataúd (cajas metálicas), bolsas de nylon, sondas, frascos de medicamentos y otros residuos de probable origen hospitalario. El sedimento matriz era discontinuo, en algunos sectores tierra negra, con signos de combustión, en otros un sedimento fluvial con pocos signos de alteración. En el cuarto nivel excavado en esta parte del sitio a poco más de setenta centímetros de profundidad, comenzó a visualizarse la continuidad de un piso de esqueletos humanos articulados, en diversas posiciones, tal cual lo presumible para un enterramiento múltiple como el que esperábamos encontrar. Se limpió la totalidad de la superficie (35 metros cuadrados) y se organizó en nueve cuadrículas de 2 metros cuadrados, denominadas según un sistema de grilla. Las nueve cuadrículas así definidas no presentaban discontinuidad en la disposición de los cuerpos, pero hacia la pared Este la unidad de depositación, denominada Piso 1 de la Cabecera Norte se veía interrumpida, por un episodio de perturbación posterior (es decir, por encima), que consistía en una matriz de sedimento negro con abundante ceniza y carbón, en el cual se hallaron numerosos restos óseos humanos no articulados, así como restos de ataúdes metálicos, todo ello compatible con residuos propios de la dinámica del 
horno crematorio. Esta interrupción corría paralela a la pared Este, y allí los esqueletos del Piso 1 se veían incompletos por este episodio posterior. En algunos de los restos in situ se podían ver signos de trauma y, no menos importante, en algunos pocos de ellos, pequeñas piezas metálicas con un número de dos o tres cifras grabado. Estas piezas se encontraban en la región del carpo, como si hubieran estado unidas a las muñecas de los cadáveres cuando estos presentaban sus tejidos blandos. Es esta una práctica compatible con el paso de los cuerpos por las morgues. La disposición aleatoria de los cuerpos y la posición en que fueron encontrados permite suponer que los mismos fueron arrojados desde el borde de la fosa, sin ningún cuidado, consideración ni otro criterio que el de una inhumación expeditiva de cadáveres. El Piso 1 terminó de ser expuesto a mediados de Marzo y desde el día 13 del mismo mes comenzó el levantamiento de los individuos, que fueron numerados de 1 al 19, con las siglas SV CN (San Vicente Cabecera Norte). Cada esqueleto fue fotografiado y se le tomaron una decena de medidas tridimensionales, para registrar su ubicación espacial en el plano general. De acuerdo a lo ordenado por la Dra. Garzón de Lascano, cada caja, con su rótulo aclaratorio y conteniendo los restos correspondientes a un individuo, fue remitida al Instituto de Medicina Forense de la ciudad de Córdoba, para su limpieza, examen y guarda en depósito. Continuada la excavación, unos treinta centímetros por debajo comenzó a despejarse un nuevo piso de esqueletos, denominado, por lo tanto, Piso 2 de la Cabecera Norte. Este segundo conjunto era mucho más abigarrado y, a idéntica superficie, se podía apreciar el resultado de otro episodio de inhumación múltiple, clandestina y simultánea. En total se recuperaron restos correspondientes a setenta y dos personas (otros tantos esqueletos articulados), además de numerosos conjuntos incompletos. Es esta la fosa común más grande, asociada al Terrorismo de Estado, que se ha excavado en Sudamérica con métodos arqueológicos. Por hallarse por debajo del Piso 1 es legítimo suponer que es más antiguo que éste. Esto se vio confirmado por el examen de las fuentes históricas. Efectivamente, también en la región del carpo de algunos individuos del Piso 2 se hallaron chapitas metálicas con números grabados. De la observación del Libro de la Morgue se puede apreciar que algunos de los cuerpos registrados durante 1976 tienen números indicativos. Estos números coinciden con los de algunas de las chapitas, en ambos pisos. De esta manera se pudo establecer la hipótesis sobre las fechas en que se produjeron estas inhumaciones. El Piso 2, el más antiguo, corresponde a una inhumación múltiple de fines de Abril de 1976 y el Piso 1, posterior y por lo tanto más cercano a la superficie, a un evento posterior, de Julio del mismo año.
La exposición del Piso 2 como totalidad se logró hacia fines de Marzo y buena parte del subsiguiente mes de Abril se dedicó al levantamiento de cada conjunto, así como de partes anatómicas, o conjuntos óseos no articulados. Una vez concluidas estas tareas se continuó la excavación en profundidad dentro de la superficie de la Cabecera Norte, sin producirse más hallazgos.

Desde fines de Abril la excavación se extendió hacia el Sur, en búsqueda de nuevos pisos indicadores de episodios de inhumación múltiple. Estas tareas no ofrecieron resultados alentadores hasta mediados de Mayo, cuando a doce metros del límite Sur de la unidad denominada Cabecera Norte, y a similar profundidad, se encontró un tercer piso de restos óseos humanos. A este conjunto se lo denominó Piso 1 de la Franja Central. La característica saliente de este conjunto (restos de al menos 32 individuos), es la alta cantidad de partes anatómicas no asociadas a un esqueleto en particular, como si se hubieran inhumado numerosos miembros seccionados junto a los esqueletos completos. La excavación del Piso 1 de la Franja Central se prolongó hasta el 18 de Junio. Posteriormente se continuó excavando en profundidad y en sus inmediaciones, y ya no se produjeron hallazgos en esta parte de la Sección C del Cementerio de San Vicente. Lo anterior confirmó la destrucción completa de la llamada Fosa Grande, de Diciembre de 1976, en las excavaciones no científicas practicadas en Marzo de 1984.

\section{Informe Antropológico Forense}

Una vez trasladados los restos desde el Cementerio de San Vicente hasta el Instituto Médico Forense (IMF) de la ciudad de Córdoba, se comenzaron los trabajos de laboratorio en la sala habilitada para tal fin, el día 28 de abril del 2003. A partir de esta fecha se realizó el estudio de laboratorio de los restos de forma permanente. Dadas las características de los esqueletos recuperados tanto en la fosa SVcbCN como SVcbFC del Cementerio de San Vicente, se presumía de manera preliminar, in situ, la existencia de dos grupos poblacionales entremezclados: un conjunto mayoritario de individuos de edad avanzada, que habrían ingresado a la morgue en el período investigado, pero que no formarían parte del universo de personas detenidas-desaparecidas; y un grupo menor de jóvenes, con signos de muerte violenta que indicaban una probable vinculación con la investigación en curso.

Con el fin de optimizar el estudio de los restos se llevó a cabo una priorización de casos previa al análisis, en función de criterios que a priori se observaran en la fosa, intentando abarcar el universo de personas que pudieran estar posiblemente relacionadas con la detencióndesaparición o muerte violenta. Los criterios seguidos en la selección atendieron a edad 


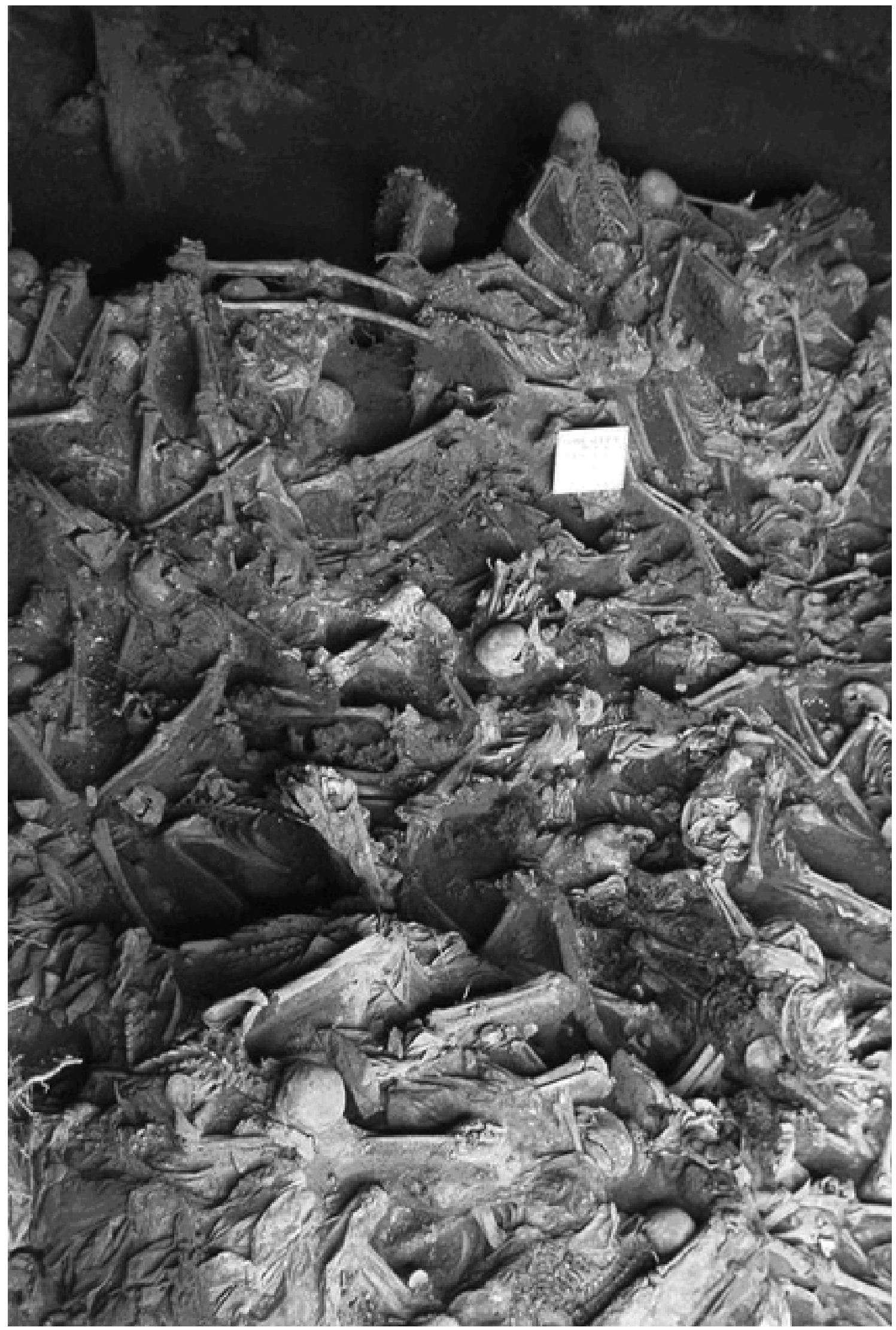

Figura 1: Cementerio de San Vicente, Sector C. Cabecera Norte, Piso 2

(priorizando adolescentes y adultos jóvenes sobre adultos seniles), signos de muerte violenta (fracturas perimortem, balística, etc), o a indicios de personas que no forman parte de una muestra regular de morgue (ropa asociada, desarticulación de los restos óseos, etc.). Dicha clasificación marcó el orden de análisis de los esqueletos recuperados, continuándose con el resto, una vez agotada la priorización previa, por orden de recuperación en la fosa. 


\section{Procedimientos}

En el contexto de la antropología forense, el objetivo del análisis de los restos óseos tiene una doble vertiente:

a) Identificación de las víctimas b) Esclarecimiento de la causa de la muerte, a través de la detección de lesiones perimortem, es decir, de signos de violencia ejercida directamente a la persona en un momento cercano al de la muerte. Para ello es imprescindible la determinación de la temporalidad de las lesiones observadas, así como su clasificación, lo que ayudará a realizar una reconstrucción retrospectiva tanto del historial premortem de la víctima (útil desde el punto de vista de su identificación), como de los hechos que pudieron llevar a su muerte (detención prolongada, posibles torturas, agente causal de las lesiones, modo de muerte, etc.). Los procedimientos generales seguidos para el análisis de los restos, se pueden resumir en una serie de pasos, que sufrieron pequeñas variaciones en función del estado de conservación o las características del caso:

Preparación de los restos: limpieza de las piezas óseas recuperadas y los artefactos y evidencias asociadas. En la mayoría de los casos se realizó una limpieza en seco con cepillos suaves, con el fin de no dañar el tejido óseo, ya que debido al estado de preservación de los restos no resultaba conveniente sumergirlos en agua.

Análisis morfológico: análisis individual de cada esqueleto en lo que se refiere a su caracterización, es decir, a la determinación de variables como sexo, edad biológica, estatura y análisis dental, así como a la reconstrucción del historial osteológico de cada persona en lo que respecta a datos sobre lesiones premortem, patologías, rasgos epigenéticos o no métricos y lesiones traumáticas ocasionadas en el hueso en un momento cercano al de la muerte (perimortem), estuvieran o no relacionadas con la causa de ésta.

Registro radiográfico en aquellos casos en que se encontraron fracturas, arreglos dentales o se sospechaba que pudieran existir fragmentos metálicos asociados al hueso, correspondientes a balística.

Registro gráfico y fotográfico de cada caso, haciendo énfasis en los hallazgos que resultaran de mayor relevancia por la información aportada principalmente en lo que respecta a los signos de violencia ejercidos al individuo (lesiones traumáticas), a hipótesis de identidad (patologías, fracturas premortem, etc.), o a variables tafonómicas (erosión, evidencias de exposición al fuego, etc.).

Todos los datos recopilados en el análisis de laboratorio fueron anotados en la ficha respectiva, elaborándose un informe individual de cada esqueleto con el resumen de los hallazgos más relevantes.

En los casos en que se recuperó ropa o efectos personales asociados al esqueleto se realizó un inventario así como un registro fotográfico de todos ellos.

Por último, se llevó a cabo una selección de objetos registrados como posible evidencia, bien por suponer signos de violencia (balística, alambres, cordeles, etc.) presuntamente ejercida a los individuos, o por aportar datos de interés para la investigación pericial (chapas metálicas con número grabado asociadas a los esqueletos), realizándose un registro fotográfico específico.

La información resultante del estudio de cada esqueleto fue contrastada con el registro testimonial de los supuestos familiares, así como con la documentación histórica (fecha de desaparición, registro en libro de morgue, etc.). En los casos en los que existían concordancias tanto con el perfil biológico de la víctima, como con la presunción documental o testimonial de inhumación en la fosa investigada, se formularon hipótesis de identidad.

Posteriormente se llevaron a cabo búsquedas de registros médicos, dentales, radiográficos, etc. de las víctimas, con el fin de corroborar la identificación. Al no contar con este tipo de registros en ninguno de los casos analizados, fue necesario acudir al análisis genético con el fin de llegar a la identificación positiva (indubitable) de las víctimas, para lo que se derivaron al laboratorio LIDMO de la ciudad de Córdoba muestras óseas de los esqueletos con hipótesis de identidad junto con muestras de sangre y mucosa bucal de los presuntos familiares.

En los casos en los que se llegó a la identificación positiva, se entregó al Juzgado Federal $\mathrm{n}^{\circ} 3$, un informe pericial individual, en el que se detallaba el proceso realizado desde la exhumación al análisis de los restos, los resultados y conclusiones del estudio, así como un registro gráfico y fotográfico de los hallazgos más relevantes.

Finalmente, los restos de las víctimas identificadas hasta el momento fueron restituidos a sus familiares conservando en custodia en el EAAF, según mandato judicial, muestras óseas y sanguíneas representativas de cada esqueleto y su familiar respectivamente, junto con la evidencia recuperada (balística, chapas de registro de morgue, etc.).

\section{Resultados}

Se completó el análisis de los 91 esqueletos exhumados en la fosa SVcb CN, y de los 32 recuperados en la fosa SVcb FC, del Cementerio de San Vicente de Córdoba.

\section{Fosa SVcb CN}

Se recuperó un total de 91 esqueletos, de los que 19 corresponden al denominado piso 1 (cuya fecha de inhumación se presume el 22 de julio de 1976), y 72 al piso 2 (con fecha verificada de inhumación el 27 de abril de 1976). El 80\% de los 
esqueletos recuperados en la totalidad de la fosa corresponden a individuos de sexo masculino. Se verificó la existencia en la fosa de dos grupos de población: un conjunto mayoritario de personas de edad superior a los 40 años (59\%) y un grupo menor con edad incluida en el rango de 15 a 40 años (41\%). Sólo 23 de los 91 esqueletos analizados presentaban evidencias de autopsia realizada en el periodo investigado, lo que significa que al $75 \%$ de los cuerpos que ingresaron en dicha fecha a la morgue, no le fue practicada autopsia médico-legal destinada a determinar la causa de la muerte. Esto implica que la mayoría de los diagnósticos de causa de muerte debieron ser realizados con base únicamente en reconocimiento externo. En 30 de los 91 esqueletos se encontraron asociadas chapas metálicas con número grabado. Desde un principio se presumió que dichas chapas correspondían al registro interno de la morgue en la que se depositaron los cuerpos, hipótesis que fue verificada tras la identificación positiva de varias de las víctimas, que presentaban este tipo de evidencia. Tanto la forma como el registro numeral de las chapas correspondientes a cada nivel de enterramiento de la fosa SVcb CN y de la fosa SVcb $\mathrm{FC}$, son diferentes, por lo que se presume que los cuerpos contenidos en cada uno de ellos proceden de lugares o períodos distintos. De los 30 esqueletos que presentaban chapa asociada, sólo 5 (17\%) mostraban signos de autopsia, por lo que la colocación del número de registro no debió atender a este criterio. Sin embargo, en el $43 \%$ de los esqueletos con chapa asociada se observaron signos de muerte violenta, mientras que esta cifra desciende al $19 \%$ en el caso de los esqueletos que no presentaban dicho registro metálico. En el caso de la edad, las cifras son aún más dispares, ya que el $62 \%$ de los esqueletos con edad biológica menor o igual a 35 años presentaban chapa asociada, mientras que sólo se encontró en el $20 \%$ de los individuos mayores de esta edad. Este hecho podría indicar que la colocación de las chapas numeradas no fue aleatoria, presumiéndose una tendencia en el personal laboral de la morgue a ubicarlas con mayor frecuencia en cuerpos jóvenes o que presentaran lesiones traumáticas, aunque en el libro de la morgue constaran como NN, es decir, como un posible intento de discriminar o resaltar de alguna manera la evidencia de cadáveres con elementos de muerte violenta. La mayor parte de los cuerpos fueron enterrados sin ropa ni efectos personales asociados. En algunos casos se verificó la correspondencia con un mismo esqueleto de partes anatómicas que se encontraban desarticuladas in situ en la fosa, sin evidencias de corte, lo que es coincidente con el hecho de que varios de los cuerpos se encontraran en avanzado estado de descomposición en el momento de la inhumación.

Aproximadamente la mitad de los esqueletos estudiados (49\%) no presentaron ningún tipo de lesión traumática perimortem (ocasionada alrededor del momento de la muerte), mientras que en el $51 \%$ restante se encontraron evidencias de dos tipos de lesiones:

- Traumas óseos indicativos de violencia (54\%).

- Fracturas postmortem (posteriores a la muerte de las personas), causadas en el hueso cuando aún existía tejido blando (46\%). Se presume que dichas lesiones están relacionadas tanto con el almacenamiento de los cuerpos en la morgue en la fecha investigada, como con su transporte y depósito en la fosa, y es indicativo del tratamiento poco cuidadoso que se dio a los cadáveres en dicho periodo.

En cuanto al tipo de lesiones perimortem indicativas de violencia ejercida a las víctimas, en los 25 esqueletos en los que se encontraron evidencias, el $88 \%$ de los casos es compatible con impactos de proyectil de arma de fuego, el $8 \%$ con lesiones contusas, y el $4 \%$ corresponde a trauma cortante. En función de dichas lesiones, se presumió la causa de la muerte en el $27 \%$ del total de los casos. La mayor parte de los esqueletos con evidencias de lesiones causadas por proyectil de arma de fuego, presentaron politraumatismo, es decir, más de un impacto. La distribución anatómica de las lesiones es variable, aunque más de la mitad de los casos (64\%) muestran lesiones en el cráneo (además de en otras áreas del cuerpo), en el 32\% se encuentran en el tronco (tórax y abdomen) y un $4 \%$ únicamente en extremidades. En los casos que presentaban lesiones por proyectil en cráneo, se encontró una predominancia de trayectorias postero-anteriores, y un número de impactos que varió desde 1 hasta 5. Se recuperó balística asociada al 12\% de los esqueletos.

Al analizar el grupo de población que presenta evidencias de dichas lesiones en función de la edad, encontramos que el $60 \%$ de las personas menores de 30 años muestra signos de violencia, mientras que la cifra se invierte a partir de dicha edad (14\%). Gran parte de los esqueletos correspondientes a este último grupo corresponde a personas de edad avanzada, con elevada frecuencia de enfermedades degenerativas, y con mala salud oral en general, y que debieron corresponder a cuerpos no reclamados (indigentes, ancianos, etc.) que ingresaron a la morgue por causas ajenas al hecho investigado.

Por otra parte, en 5 de los esqueletos correspondientes al piso 2 (con fecha de inhumación datada el 27 de abril de 1976), se encontraron indicios de lepra (con afectación del tejido óseo en miembros inferiores). Cuatro de estos esqueletos se encontraron juntos en el sector sur de la fosa, y ninguno de ellos tenía asociada chapa numerada con registro de morgue. Por indagaciones llevadas a cabo con personal médico experto en el tema, se averiguó que existía un hospital transitorio para enfermos de lepra, anexo al Cementerio de San Vicente, que funcionó desde 1965 hasta 1979. Es posible que el traslado de dichos cuerpos hasta la fosa fuese directo, sin pasar por la morgue, lo que explicaría 
que no exista concordancia entre el número de esqueletos encontrados y el registrado en el libro de la morgue (Salado Puerto et al. 2005).

Por último, hasta el momento se ha logrado la identificación positiva de diez víctimas, verificada a través de análisis genético. Sus restos fueron restituidos a los familiares. La identificación de estas diez personas permite verificar la datación de las inhumaciones en la fosa SVcbCN del Cementerio de San Vicente (27 de abril de 1976, 22 de julio y 29 de agosto de 1976), corroborar que se trata de enterramientos clandestinos, sin registro en el libro del cementerio y sin actas de defunción de las víctimas. Por otra parte, en función de las fechas de desaparición (según información testimonial y/o documental, dichas víctimas fueron detenidas en el período de diciembre de 1975 a abril de 1976), de entrada en la morgue (registro documental) y de enterramiento, se corrobora el hecho de que los cuerpos fueron depositados en la morgue por un largo período de tiempo, y trasladados juntos a la fosa común.

\section{Fosa SVcb FC}

Se recuperó un total de 32 esqueletos, presumiblemente procedentes de un mismo evento de inhumación, en el que la mayor parte de los cuerpos fueron enterrados sin ropa ni efectos personales asociados, directamente en la fosa sin ningún tipo de cajón o ataúd. La mayoría de ellos se encontraron incompletos, con un grado severo de erosión y polifragmentación postmortem, lo que dificultó el análisis morfológico de los restos, limitando en gran medida la obtención de resultados. La distribución de los esqueletos por sexo y edad difiere de la encontrada en la fosa SVcb $\mathrm{CN}$, contándose con un $50 \%$ de individuos de cada sexo y con una mayor proporción de personas de edad superior a los 40 años (75\%) que en la fosa descrita anteriormente. En este caso, el $94 \%$ de las mujeres corresponden a adultos mayores de 40 años, principalmente seniles. Del mismo modo que en la fosa SVcb CN, sólo 6 de los 32 esqueletos analizados presentan evidencias de autopsia realizada en el periodo investigado, lo que significa que al $81 \%$ de los cuerpos que ingresaron en dicha fecha a la morgue, no le fue practicada autopsia médico-legal destinada a determinar la causa de la muerte. Sólo 2 esqueletos presentaban asociadas chapas metálicas con número grabado, con forma y numeración que difiere de las recuperadas en la fosa SVcb CN. En ambos casos se trata de individuos con edad igual o inferior a 35 años, con evidencias de muerte violenta y sin indicios de autopsia, lo que sigue indicando que su colocación no debió ser aleatoria, presumiéndose como describíamos en la fosa anterior una tendencia en el personal laboral de la morgue a ubicarlas con mayor frecuencia en cuerpos jóvenes o que presentaran lesiones traumáticas A diferencia de la fosa SVcb CN, la mayoría de los esqueletos no mostró evidencias de lesiones traumáticas perimortem (ocasionadas alrededor del momento de la muerte), encontrándose en el 25\% de ellos los dos tipos descritos:

- Traumas óseos indicativos de violencia (62\%).

- Fracturas postmortem (posteriores a la muerte de las personas), causadas en el hueso cuando aún existía tejido blando (38\%), relacionadas presumiblemente con el almacenamiento de los cuerpos en la morgue en la fecha investigada, así como con su transporte y depósito en la fosa, y es indicativo del tratamiento poco cuidadoso que se dio a los cadáveres en dicho periodo.

En los 5 esqueletos en los que se encontraron signos de violencia, los traumas óseos perimortem son compatibles con lesiones causadas por impactos de proyectil de arma de fuego.

En función del análisis patológico, se presumió la causa de la muerte en 6 de los 32 esqueletos, tratándose en el $83 \%$ de dichos casos de politraumatismos causados por impactos de proyectil de arma de fuego, y en el caso restante (17\%) por causa natural (con diagnóstico presuntivo de muerte por metástasis tumoral).

Todos los esqueletos con evidencias de lesiones causadas por proyectil de arma de fuego, presentaron politraumatismo, es decir, más de un impacto (en un rango de 2 a 5). La distribución anatómica de las lesiones es variable, encontrándose lesiones en el cráneo, tronco (tórax y abdomen) y extremidades. No se observaron patrones fijos de distribución. Sin embargo, se encontró una predominancia de trayectorias postero-anteriores del proyectil. Se recuperó balística asociada a 2 de los esqueletos.

Únicamente 1 de los 5 casos en los que se encontraron evidencias de lesiones traumáticas perimortem presentaban signos de autopsia, lo que sigue indicando que el diagnóstico de causa de muerte que se llevó a cabo en el período investigado en el resto de los cadáveres fue realizado con base únicamente en el reconocimiento del cuerpo.

Todos los esqueletos con evidencias de lesiones causadas por impactos de proyectil de arma de fuego corresponden a personas de sexo masculino y el $80 \%$ son menores de 40 años. Este hecho corrobora la existencia de dos grupos de población: un conjunto menor de personas jóvenes con mayor frecuencia de signos de muerte violenta y un subgrupo mayoritario de personas de edad superior a 40 años, con baja frecuencia de lesiones traumáticas perimortem. Al igual que en la fosa SVcb CN, la mayoría de los esqueletos incluidos en este último grupo corresponde a personas de edad avanzada, con elevada frecuencia de enfermedades degenerativas, y con mala salud oral en general, y que debieron corresponder a cuerpos no reclamados (indigentes, ancianos, etc.) que ingresaron a la morgue por causas ajenas al hecho investigado. 
Las tres identificaciones correspondientes a restos hallados en esta fosa que se han establecido a la fecha, permiten inferir, cruzando con la información histórica, que la inhumación corresponde al 29 de agosto de 1976.

\section{Conclusiones}

En la actualidad, es inminente el inicio de las audiencias públicas que darán inicio al juzgamiento de los responsables por estos hechos. Continuamos abocados a la toma de muestras de sangre de familiares de desaparecidos en Córdoba para el intervalo de tiempo comprendido por las fosas de San Vicente, para su comparación de material genético con el recuperado en los restos óseos.

Muchas personas del EAAF y fuera de él colaboraron en esta tarea, dar los nombres de setenta personas no es lo indicado en este tipo de comunicaciones, pero sin el aporte de cada una de ellas no hubiéramos llegado al punto donde ahora nos encontramos, habiendo logrado recuperar la identidad de trece desaparecidos y esperando aumentar esa cifra en los próximos meses.

\section{Bibliografía}

Olmo, D. (comp). 2005. Equipo Argentino de Antropología Forense «Cementerio de San Vicente Informe 2003». Ferreyra Editor, Córdoba.

Salado Puerto, M., D. Olmo y L. Fondebrider. 2005. El aporte del análisis patológico en el contexto Antropológico Forense, estudio de casos en una fosa clandestina Córdoba. III Congreso de la Asociación Latinoamericana de Antropología Forense, ALAF, Bogotá
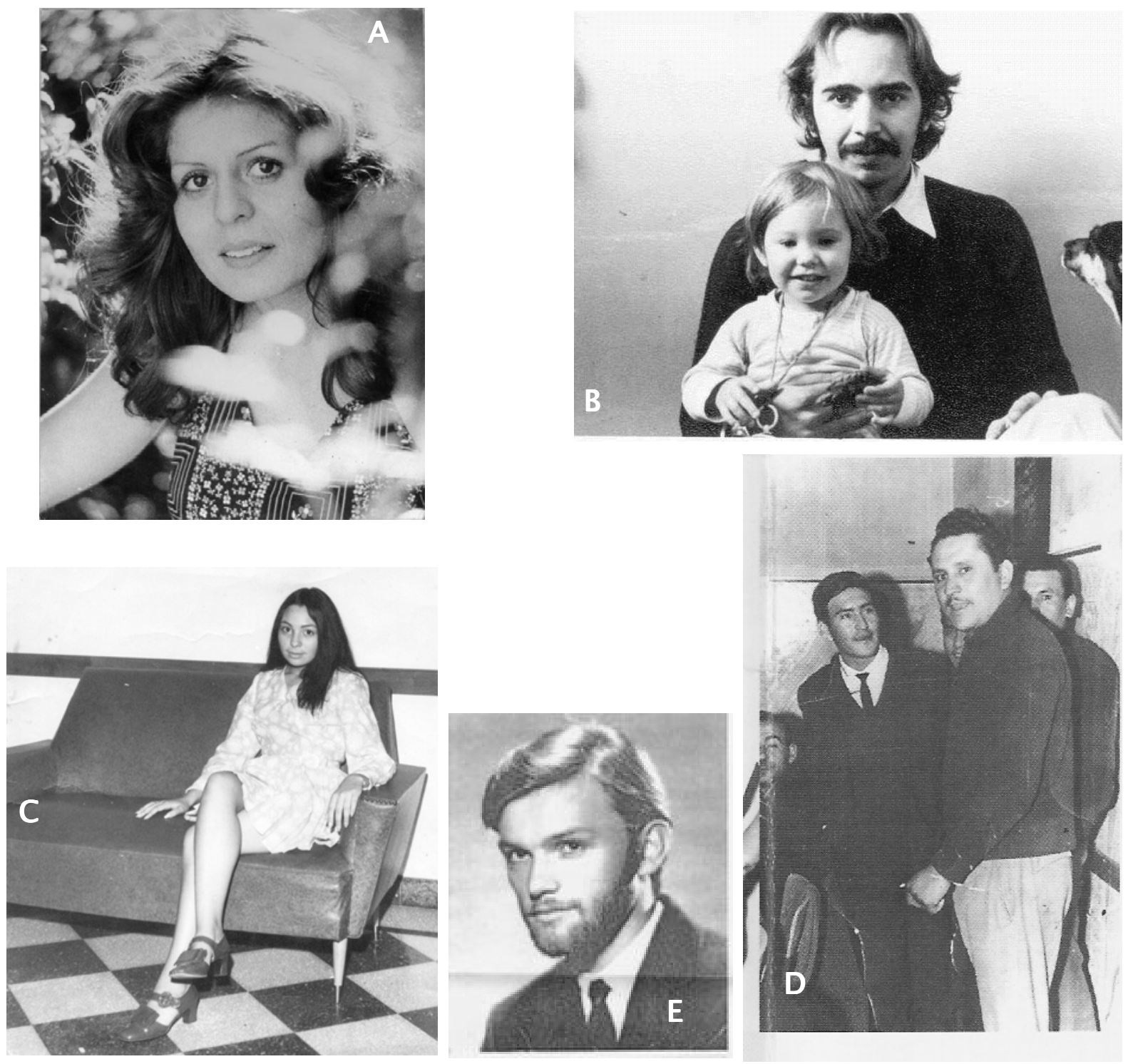

Fotos de identificados. A: Torres; B: Alvarez; C: Palacios; D: Hugo; E: Juan. 